\title{
Synthesis and antimicrobial evaluation of two peptide LyeTx I derivatives modified with the chelating agent HYNIC for radiolabeling with technetium-99m
}

Leonardo Lima Fuscaldi ${ }^{1}$, Daniel Moreira dos Santos², Natália Gabriela Silva Pinheiro³, Raquel Silva Araújo ${ }^{1}$, André Luís Branco de Barros ${ }^{1}$, Jarbas Magalhães Resende ${ }^{3}$, Simone Odília Antunes Fernandes ${ }^{1}$,

Maria Elena de Lima ${ }^{2}$ and Valbert Nascimento Cardoso ${ }^{1 *}$

\begin{abstract}
Background: Current diagnostic methods and imaging techniques are not able to differentiate septic and aseptic inflammation. Thus, reliable methods are sought to provide this distinction and scintigraphic imaging is an interesting option, since it is based on physiological changes. In this context, radiolabeled antimicrobial peptides have been investigated as they accumulate in infectious sites instead of aseptic inflammation. The peptide LyeTx I, from the venom of Lycosa erythrognatha, has potent antimicrobial activity. Therefore, this study aimed to synthesize LyeTx I derivatives with the chelating compound HYNIC, to evaluate their antimicrobial activity and to radiolabel them with ${ }^{99 \mathrm{~m}} \mathrm{Tc}$.
\end{abstract}

Methods: Two LyeTx I derivatives, HYNIC-LyeTx I (N-terminal modification) and LyeTx I-K-HYNIC (C-terminal modification), were synthesized by Fmoc strategy and purified by RP-HPLC. The purified products were assessed by RP-HPLC and MALDI-ToF-MS analysis. Microbiological assays were performed against S. aureus (ATCC ${ }^{\circledR} 6538$ ) and E. coli (ATCC ${ }^{\oplus}$ 10536) in liquid medium to calculate the MIC. The radiolabeling procedure of LyeTx I-K-HYNIC with ${ }^{99 \mathrm{~m}} \mathrm{Tc}$ was performed in the presence of co-ligands (tricine and EDDA) and reducing agent $\left(\mathrm{SnCl}_{2} 2 \mathrm{H}_{2} \mathrm{O}\right)$, and standardized taking into account the amount of peptide, reducing agent, $\mathrm{pH}$ and heating. Radiochemical purity analysis was performed by thin-layer chromatography on silica gel strips and the radiolabeled compound was assessed by RP-HPLC and radioactivity measurement of the collected fractions. Data were analyzed by ANOVA, followed by Tukey test ( $p$-values $<0.05$ ).

Results: Both LyeTx I derivatives were suitably synthesized and purified, as shown by RP-HPLC and MALDI-ToF-MS analysis. The microbiological test showed that HYNIC-LyeTx I (N-terminal modification) did not inhibit bacterial growth, whereas LyeTX I-K-HYNIC (C-terminal modification) showed a MIC of $5.05 \mu \mathrm{mol} \cdot \mathrm{L}^{-1}$ (S. aureus) and $10.10 \mu \mathrm{mol} \mathrm{L}^{-1}$

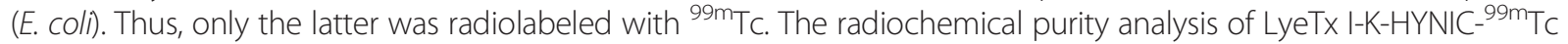
showed that the optimal radiolabeling conditions $\left(10 \mu \mathrm{g}\right.$ of LyeTx I-K-HYNIC; $250 \mu \mathrm{g}$ of SnCl $22 \mathrm{H}_{2} \mathrm{O} ; \mathrm{pH}=7$; heating for $15 \mathrm{~min}$ ) yielded a radiochemical purity of $87 \pm 1 \%(n=3)$. However, RP-HPLC data suggested ${ }^{99 \mathrm{~m}} \mathrm{TC}$ transchelation from LyeTx I-K-HYNIC to the co-ligands (tricine and EDDA).

(Continued on next page)

\footnotetext{
* Correspondence: valbertncardoso@gmail.com

${ }^{1}$ Department of Clinical and Toxicological Analyses, School of Pharmacy,

Federal University of Minas Gerais, Av. Antônio Carlos, 6627, Belo Horizonte,

MG 31270-901, Brazil

Full list of author information is available at the end of the article
} 
(Continued from previous page)

Conclusions: The binding of HYNIC to the N-terminal portion of LyeTx I seems to affect its activity against bacteria. Nevertheless, the radiolabeling of the C-terminal derivative, LyeTX I-K-HYNIC, must be better investigated to optimize the radiolabeled compound, in order to use it as a specific imaging agent to distinguish septic and aseptic inflammation.

Keywords: Septic and aseptic inflammation, Differential diagnosis, Antimicrobial peptides, LyeTx I derivatives, MALDI-ToF-MS, RP-HPLC, Technetium-99m, HYNIC, EDDA, Tricine

\section{Background}

Inflammatory processes can be divided into two categories: septic (induced by bacteria or fungi) or aseptic (absence of microorganisms) inflammation [1]. Thus, differential diagnosis is required to determine the most suitable therapeutic approach. In some cases, such as bone inflammation, current diagnostic methods and conventional imaging techniques are not able to differentiate septic and aseptic inflammation. Therefore, alternatives must be found in order to ensure an accurate diagnosis. In this sense, scintigraphic imaging is a promising approach since it is based on physiological changes, which occur earlier than anatomical modifications [2-4]. In this context, radiolabeled antimicrobial peptides have been investigated as possible suitable tools, since they accumulate in infectious sites instead of in aseptic inflammatory lesions, once they preferentially bind to bacteria and fungi [5-7].

The cationic peptide LyeTx I was primarily isolated from Lycosa erythrognatha venom. After its purification and characterization, it was obtained by chemical synthesis. The peptide is composed of 25 amino acid residues and carries a natural carboxyl-terminal (C-terminal) carboxyamide (H-IWLTALKFLGKNLGKHLAKQQLAKL-NH ${ }_{2}$ ). LyeTx I exhibits antimicrobial activity against microorganisms, such as Escherichia coli, Staphylococcus aureus, Candida krusei and Cryptococcus neoformans [8]. Therefore, radioisotope-labeled LyeTx I may be an interesting strategy for a specific imaging probe for infections.

The radioisotope technetium- $99 \mathrm{~m}\left({ }^{99 \mathrm{~m}} \mathrm{Tc}\right)$ presents suitable features for its administration to patients in nuclear medicine. This radionuclide emits gamma rays of low energy $(\sim 140 \mathrm{keV})$ and has physical half-life of 6.02 h. ${ }^{99 \mathrm{~m}} \mathrm{Tc}$ exposes patients to low radiation doses whereas it is widely used for radiolabeling molecules employed as scintigraphic imaging probes. Furthermore, this radioisotope is easily obtained from a low cost molibdenium-99/technetium- $99 \mathrm{~m} \quad\left({ }^{99} \mathrm{Mo} /{ }^{99 \mathrm{~m}} \mathrm{Tc}\right)$ generator $[9,10]$. However, in order to use ${ }^{99 \mathrm{~m}} \mathrm{Tc}$ for radiolabeling peptides without disulfide bonds, such as LyeTx I, it is necessary to attach a chelating agent to the amino acid sequence. In this sense, 2-hydrazinonicotinamide (HYNIC) is a good option, since its carboxylic acid group reacts directly with the nitrogen-terminal (N-terminal) residue or alternatively with the lateral amino group of a lysine residue present in the peptide sequence. However, an extra lysine may be coupled to the C-terminal portion in order to maintain the peptide sequence with a minor change. Lastly, to stabilize ${ }^{99 \mathrm{~m}} \mathrm{Tc}$ binding to HYNIC, tricine and ethylenediamine- $\mathrm{N}, \mathrm{N}^{\prime}$ diacetic acid (EDDA) are used as co-ligands in the radiolabeling procedure [11-13].

Therefore, this study aimed to synthesize two peptide LyeTx I derivatives modified with the chelating agent HYNIC, to evaluate the maintenance of its antimicrobial activity and to standardize its radiolabeling with ${ }^{99 \mathrm{~m}} \mathrm{Tc}$ atoms.

\section{Methods \\ Materials}

Amino acid derivatives for peptide synthesis were purchased from Iris Biotech GmbH (Marktredwitz, Germany). Trifluoroacetic acid (TFA) and triisopropylsilane were obtained from Sigma-Aldrich (Saint Louis, USA). 1,3-diisopropylcarbodiimide was acquired from Fluka (Steinheim, Germany). 1-hydroxybenzotriazole was purchased from NovaBiochem-Merck (Darmstadt, Germany). N,Ndimethylformamide (DMF) and diisopropyl ether were obtained from Vetec (Duque de Caxias, Brazil). Acetonitrile (HPLC grade) was acquired from JT Baker (Center Valley, USA). If not mentioned otherwise, analytical grade solvents were used. All solvents used in reverse phase-high performance liquid chromatography (RP-HPLC) system (HPLC grade) were purchased from Tedia (Rio de Janeiro, Brazil). Ultrapure water, obtained through MilliQ ${ }^{\circ}$ system of Millipore (Darmstadt, Germany), was used throughout. The bacterial strains of reference, S. aureus (ATCC ${ }^{\circ}$ 6538) and $E$. coli (ATCC 10536), were acquired from American Type Culture Collection - ATCC (Manassas, USA). ${ }^{99 \mathrm{~m}} \mathrm{Tc}$ was obtained from a ${ }^{99} \mathrm{Mo} /{ }^{99 \mathrm{~m}} \mathrm{Tc}$ generator supplied by the Nuclear Energy Research Institute - IPEN (São Paulo, Brazil). Other reagents and solvents for the radiolabeling procedure were acquired from Sigma-Aldrich (São Paulo, Brazil).

\section{Synthesis and purification of two peptide LyeTx I} derivatives modified with the chelating agent HYNIC Two peptide LyeTx I derivatives with the chelating agent HYNIC attached either to its N-terminal residue (HYNIC- 
LyeTx I) or to its C-terminal portion (LyeTx I-K-HYNIC) were synthesized and purified, as previously reported [14].

Both synthesis were performed by stepwise solid-phase using the N-9-fluorenylmethyloxycarbonyl (Fmoc) strategy on a rink amide resin $\left(0.63 \mathrm{mmol}^{-1}\right)$. Side chain protecting groups were as follows: $t$-butyl for threonine, $t$-butyloxycarbonyl for lysine and tryptophan, (triphenyl) methyl for histidine, asparagine and glutamine. Couplings were performed with 1,3-diisopropylcarbodiimide/1-hydroxybenzotriazole in DMF for 60-180 min. Deprotections (15 min, twice) were conducted by piperidine: DMF $(1: 4 ; \mathrm{v}: \mathrm{v})$. Cleavage from the resin and final deprotection were performed with TFA/water/triisopropylsilane $(95.0 / 2.5 / 2.5, \mathrm{v}: \mathrm{v})$ at room temperature during $90 \mathrm{~min}$. Post-precipitation of the products with cold diisopropyl ether, the crude peptide complexes were extracted with water:acetonitrile $(1: 1 ; \mathrm{v}: \mathrm{v})$, followed by freeze-drying.

The crude synthetic products were purified by RPHPLC on a C8 column (Discovery BIO Wide Pore C8 column, $5 \mu \mathrm{m}, 250.0 \mathrm{~mm} \times 4.6 \mathrm{~mm}$ ), previously equilibrated with $0.1 \%$ (v:v) TFA in water (eluent A) and eluted by a linear gradient of $0.1 \%$ (v:v) TFA in acetonitrile (eluent B), as specified in Table 1A.

The collected fractions were assessed by matrixassisted laser desorption ionization time of flight mass spectrometer (MALDI-ToF-MS) analysis on AutoFlex III (Bruker Daltonics ${ }^{\circ}$, Germany). Briefly, samples were spotted onto a sample plate (MTP 384 Anchorchip, Bruker Daltonics ${ }^{\circ}$, Germany) mixed with a saturated solution of $\alpha$-cyano-4-hydroxycinnamic acid and allowed to dry at room temperature (dried-droplet method). The mass spectrometer (MS) spectra were acquired in the positive reflector mode with external calibration (Peptide Calibration Standard II, Bruker Daltonics ${ }^{\oplus}$, Germany).

\section{Purity assessment of the peptide LyeTx I derivatives modified with the chelating agent HYNIC}

The purified synthetic products were analyzed by RPHPLC on a C18 analytical column (PepMap C18 ${ }^{\text {TM }}$ column, $5 \mu \mathrm{m}, 150.0 \mathrm{~mm} \times 4.6 \mathrm{~mm}$ ), previously equilibrated with $0.1 \%(\mathrm{v}: \mathrm{v})$ TFA in water (eluent A) and eluted by a linear gradient of $0.1 \%$ (v:v) TFA in acetonitrile (eluent B), as specified in Table 1B. The peaks of the peptides were collected and analyzed by MALDIToF-MS on AutoFlex III (Bruker Daltonics ${ }^{\circ}$, Germany), as described in the previous section.

\section{In vitro evaluation of the maintenance of the antimicrobial activity of the peptide LyeTx I derivatives modified with the chelating agent HYNIC}

The maintenance of the antimicrobial activity after peptide LyeTx I modifications with HYNIC was evaluated by microdilution test, according to the Clinical and Laboratory Standards Institute [15]. Bacterial strains of reference, S. aureus (ATCC ${ }^{\circ}$ 6538) and E. coli (ATCC 10536), were grown on tryptic soy agar at $37^{\circ} \mathrm{C}$ for $18 \mathrm{~h}$. Then, 0.5 McFarland scale bacterial suspensions $\left(10^{8} \mathrm{CFU} \cdot \mathrm{mL}^{-1}\right)$ were prepared on tryptic soy broth (TSB). The readouts were carried by determination of minimum inhibitory concentration (MIC), defined as a reduction of $100 \%$ in bacterial growth post-incubation with the peptide LyeTx I derivatives at $37{ }^{\circ} \mathrm{C}$ for $24 \mathrm{~h}$. LyeTx I obtained by chemical synthesis and without the coupled chelating agent was used as treatment control. Only TSB (no bacterial suspension and no peptide) was used as negative control. TSB plus bacterial suspension (no peptide) were used as positive control. MIC was expressed as median $(n=3)$. Each replicate was performed with a different bacterial colony, in duplicate.

\section{Radiolabeling and radiochemical purity of LyeTx I-K-HYNIC with ${ }^{99 \mathrm{~m}} \mathrm{Tc}$}

The radiolabeling procedure of LyeTx I-K-HYNIC with ${ }^{99 \mathrm{~m}} \mathrm{Tc}$ and radiochemical purity analysis were performed as previously reported elsewhere [16], with some modifications. Briefly, in a sealed vial, tricine $(20 \mathrm{mg})$ and EDDA (5 mg) were solubilized in $0.9 \% \mathrm{NaCl}(\mathrm{w}: \mathrm{v})$ solution $(200 \mu \mathrm{L})$. Next, LyeTx I-K-HYNIC $(5,10$ or $20 \mu \mathrm{g})$ and $1 \mathrm{mg}^{-1} \mathrm{~mL}^{-1} \mathrm{SnCl}_{2} 2 \mathrm{H}_{2} \mathrm{O}$ solution $(100,200,250$ or $300 \mu \mathrm{L})$ in $0.25 \mathrm{~mol} \mathrm{~L}^{-1} \mathrm{HCl}$ were added. Then, the $\mathrm{pH}$ was adjusted $\left(5,6,7,8\right.$ or 9). Finally, $\mathrm{Na}^{99 \mathrm{~m}} \mathrm{TcO}_{4}$ (37 MBq; q.s. $\mathrm{ad}=1000 \mu \mathrm{L}$ ) was added to the vial and the final solution was heated $\left(100{ }^{\circ} \mathrm{C}\right)$ in water bath $(5$,

Table 1 Solvent conditions for RP-HPLC

\begin{tabular}{|c|c|c|c|c|c|}
\hline \multicolumn{2}{|c|}{ (A) Crude synthetic product purification } & \multicolumn{2}{|c|}{ (B) Purified synthetic product analysis } & \multicolumn{2}{|c|}{ (C) LyeTx I-K-HYNIC- ${ }^{99 m} \mathrm{Tc}$ evaluation } \\
\hline Time & Gradient of eluent B & Time & Gradient of eluent B & Time & Gradient of eluent B \\
\hline (min) & $(\%)$ & $(\min )$ & (\%) & $(\min )$ & $(\%)$ \\
\hline $0-8.2$ & 0 & $0-3.7$ & 0 & $0-5.0$ & 0 \\
\hline $8.2-12.4$ & $0-30$ & $3.7-33.5$ & $0-100$ & $5.0-30.0$ & $0-55$ \\
\hline $12.4-50.0$ & $30-55$ & $33.5-39$ & 100 & $30.0-35.0$ & $55-100$ \\
\hline $50.0-54.0$ & $55-100$ & & & $35.0-45.0$ & 100 \\
\hline $54.0-62.5$ & 100 & & & & \\
\hline
\end{tabular}


15 or $30 \mathrm{~min}$ ) or not heated. Radiochemical purity analysis of LyeTx I-K-HYNIC- ${ }^{99 \mathrm{~m}} \mathrm{Tc}$ was performed by thin-layer chromatography on silica gel strips $\left(\right.$ Merck $\left.^{\odot}\right)$. Methyl ethyl ketone (MEK) and acetonitrile:water (1:1; v:v) were used to determine the amount of free technetium $\left({ }^{99 \mathrm{~m}} \mathrm{TcO}_{4}^{-}\right)$and hydrolyzed technetium $\left({ }^{99} \mathrm{~m}_{\mathrm{TcO}}\right)$, respectively. Radioactivity was measured using an automatic gamma counter (Wizard, Finland).

\section{LyeTx I-K-HYNIC- ${ }^{99 m}$ Tc evaluation}

LyeTx I-K-HYNIC- ${ }^{99 \mathrm{~m}}$ Tc was evaluated as previously described [17], by RP-HPLC on a C8 column (ACE 5 C8 column, $5 \mu \mathrm{m}, 250.0 \mathrm{~mm} \times 4.6 \mathrm{~mm}$ ), previously equilibrated with $0.1 \%$ (v:v) TFA in water (eluent A) and eluted by a linear gradient of $0.1 \%(\mathrm{v}: \mathrm{v})$ TFA in acetonitrile (eluent B), as specified in Table 1C. LyeTx I-KHYNIC, EDDA and tricine were separately injected and the detection was at $214 \mathrm{~nm}$. LyeTx I-K-HYNIC- ${ }^{99 \mathrm{~m}} \mathrm{Tc}$ was injected, the fractions were collected and the radioactivity was measured using an automatic gamma counter (Wizard, Finland).

\section{Statistical analysis}

Quantitative data were expressed as mean \pm standard deviation (SD). Means were compared using Analysis of Variance (ANOVA), followed by Tukey multiple comparisons test. $p$-values $<0.05$ were considered significant. Data were analyzed using the Prism software (version 5.0).

\section{Results and discussion}

Synthesis, purification and purity assessment of two peptide LyeTx I derivatives modified with the chelating agent HYNIC

Two peptide LyeTx I derivatives were synthesized with the chelating agent HYNIC attached either to its Nterminal residue (Fig. 1a) or to the lateral amino group of an extra lysine residue coupled to its C-terminal portion (Fig. 1b). The synthetic crude products were purified by RP-HPLC (Fig. 2a, b) and the collected fractions were assessed by MALDI-ToF-MS analysis. Pure products with m/z 2966 (Fig. 2c) and m/z 3094 (Fig. 2d) were detected.

The synthetic pure products were assessed by RPHPLC (Fig. 3). Both chromatograms exhibited single and well-defined peak of the respective peptide LyeTx I derivative in high purities: $93.36 \pm 0.43 \%$ (HYNIC-LyeTx I) and $97.13 \pm 0.23 \%$ (LyeTx I-K-HYNIC). Both peaks were collected and analyzed by MALDI-ToF-MS. Data showed similar MS spectra as those previously presented (Fig. 2c, d).

These findings indicated that both synthetic peptide LyeTx I derivatives were suitably synthesized and purified. Thus, the synthetic products were available for further evaluation of the antimicrobial activity.

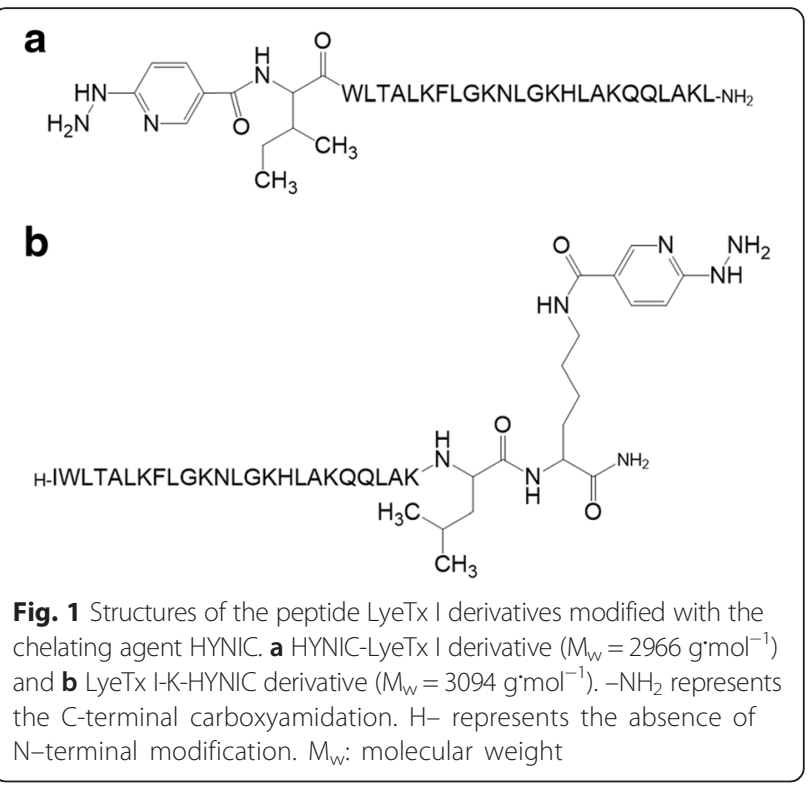

In vitro evaluation of the maintenance of the antimicrobial activity of the peptide LyeTx I derivatives modified with the chelating agent HYNIC

The maintenance of the antimicrobial activity after peptide LyeTx I chemical modifications was assessed by means of microdilution test, followed by incubation with $S$. aureus and E. coli in TSB. Table 2 summarizes in vitro microbiological assay data.

Previous data obtained for the non-modified peptide LyeTx I showed MIC's of $3.79 \mu \mathrm{mol} \cdot \mathrm{L}^{-1}$ and $7.81 \mu \mathrm{mol} \cdot \mathrm{L}$

${ }^{-1}$ for $S$. aureus and E. coli, respectively [8]. However, different assay conditions and other bacterial strains were employed, which can explain the slight differences in the MIC obtained in this study. The peptide LyeTx IK-HYNIC derivative (C-terminal modification) maintained its antimicrobial activity, exhibiting similar MIC for S. aureus and about two-fold higher MIC for E. coli, when compared to the non-modified peptide. On the other hand, the peptide HYNIC-LyeTx I derivative (Nterminal modification) did not inhibit bacterial growth (NI: no inhibition). Thus, the N-terminal modification suppressed the antimicrobial activity of peptide HYNICLyeTx I derivative, suggesting that the $\mathrm{N}$-terminal portion is important for the peptide interaction with bacteria. Therefore, only the peptide LyeTx I-K-HYNIC derivative was selected for further radiolabeling with ${ }^{99 \mathrm{~m}} \mathrm{Tc}$, in order to be tested as a specific imaging probe for infectious.

\section{Radiolabeling and radiochemical purity of LyeTx I-K- HYNIC with ${ }^{99 \mathrm{~m}} \mathrm{Tc}$}

As the peptide HYNIC-LyeTx I derivative did not exhibit any antimicrobial activity, the radiolabeling process was performed only with the peptide LyeTx IK-HYNIC derivative. 


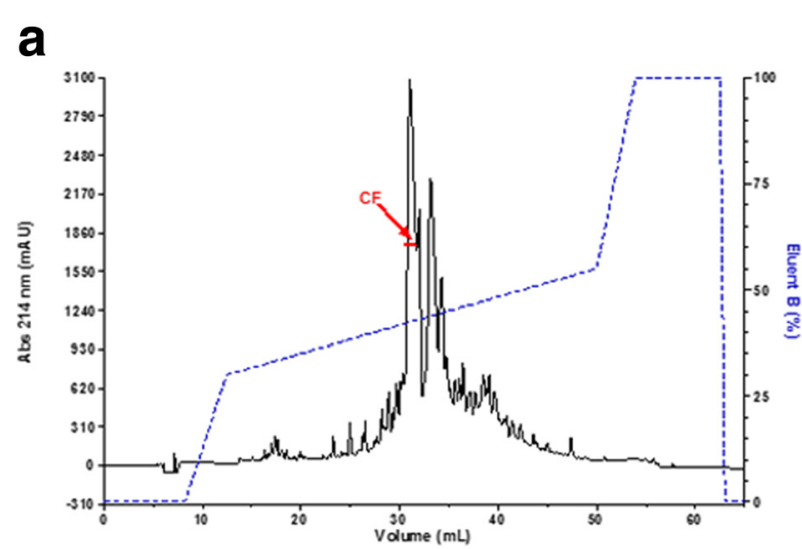

\section{C}

b

d
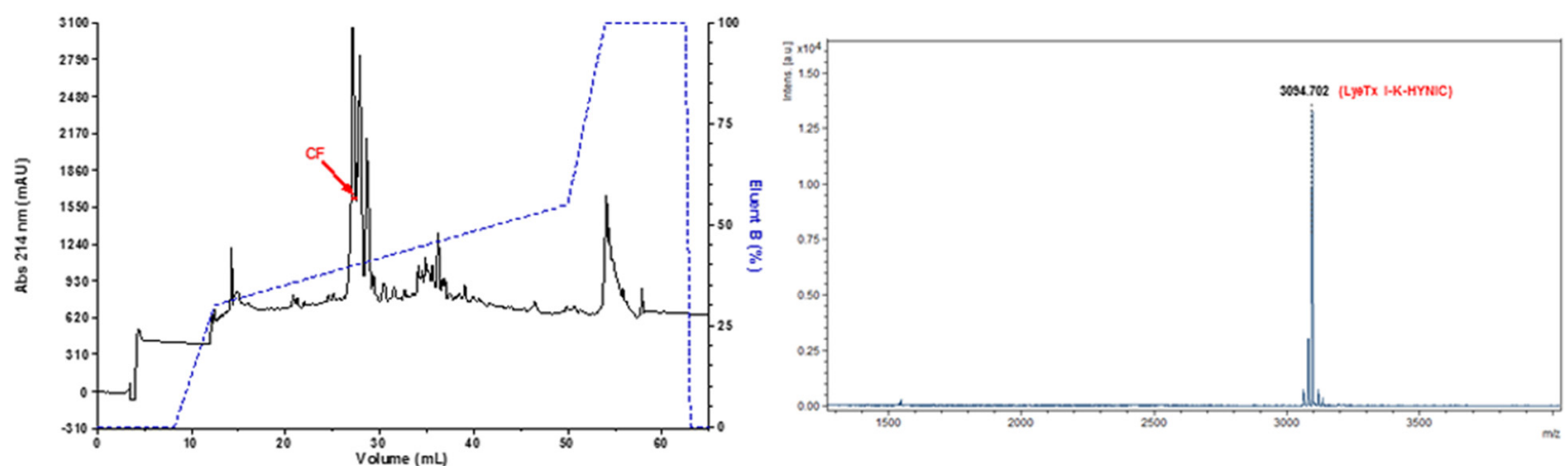

Fig. 2 Purification of synthetic crude peptide LyeTx I derivatives modified with the chelating agent HYNIC, by RP-HPLC (Ettan LC, GE HealthCare, USA), Chromatograms of synthetic crude a HYNIC-LyeTx I and $\mathbf{b}$ LyeTx I-K-HYNIC: Discovery ${ }^{\circledast}$ BIO Wide Pore C8 column $(5 \mu \mathrm{m}, 250.0 \mathrm{~mm} \times 4.6 \mathrm{~mm})$ equilibrated with $0.1 \%(\mathrm{v}: \mathrm{v})$ TFA in water (eluent A) and eluted by a linear gradient of $0.1 \%$ (v:v) TFA in acetonitrile (eluent B); the flow was $1.0 \mathrm{~mL} \cdot \mathrm{min}^{-1}$ and the detection was at $214 \mathrm{~nm}$. Mass spectrometer (MS) spectra of the collected fraction (CF) of synthetic purified $\mathbf{c}$ HYNIC-LyeTX I and d LyeTx I-K-HYNIC: the molecular weights were $2966 \mathrm{Da}$ and 3094 Da, respectively, obtained by deconvolution of the MS spectra

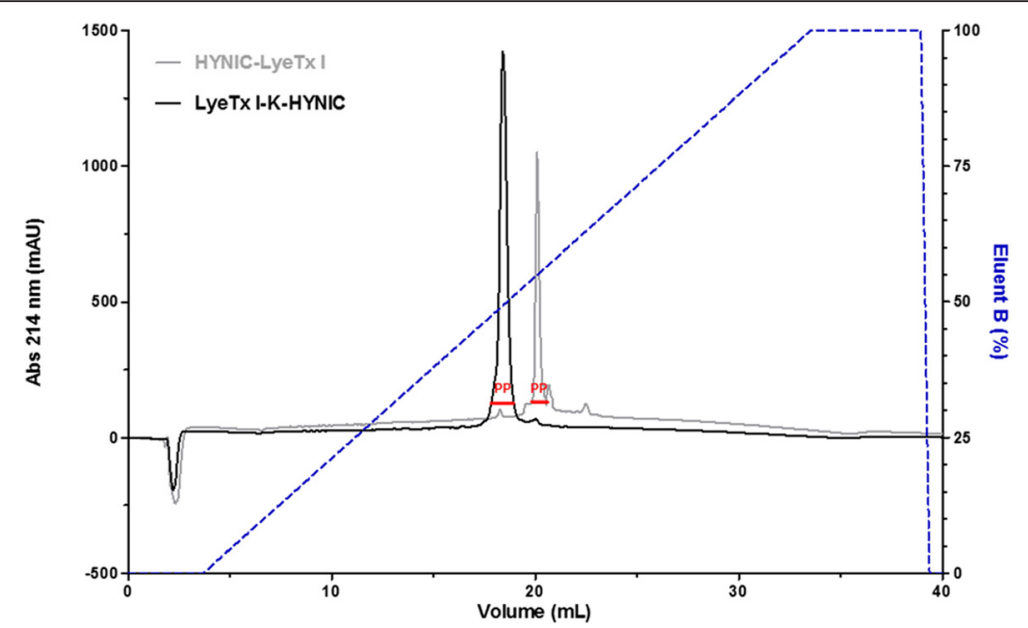

Fig. 3 Purity assessment of synthetic purified peptide LyeTx I derivatives modified with the chelating agent HYNIC, by RP-HPLC (Ettan LC, GE HealthCare, USA). Chromatograms of synthetic purified HYNIC-LyeTx I (gray line) and LyeTx I-K-HYNIC (black line): PepMap C18 ${ }^{\text {TM }}$ column (5 $\mu$ m, $150.0 \mathrm{~mm} \times 4.6 \mathrm{~mm}$ ) equilibrated with $0.1 \%(\mathrm{v}: \mathrm{v})$ TFA in water (eluent A) and eluted by a linear gradient of $0.1 \%$ (v:v) TFA in acetonitrile (eluent B); the flow was $1.0 \mathrm{~mL} \cdot \mathrm{min}^{-1}$ and the detection was at $214 \mathrm{~nm}$. PP: peak of peptide 
Table 2 Minimum inhibitory concentration (MIC) of LyeTx I (control), LyeTx I-K-HYNIC and HYNIC-LyeTx I against S. aureus and E. coli in TSB

\begin{tabular}{lll}
\hline Peptide & $\begin{array}{l}\text { S. aureus } \\
\text { (ATCC }\end{array}$ & $\begin{array}{l}\text { E. coli } \\
\text { (ATCC }\end{array}$ \\
\hline $\begin{array}{l}\text { LyeTx 1053) I (non-modified peptide) } \\
\text { LyeTx I-K-HYNIC (C-terminal }\end{array}$ & $5.52 \mu \mathrm{mol} \cdot \mathrm{L}^{-1}$ & $5.52 \mu \mathrm{mol} \cdot \mathrm{L}^{-1}$ \\
$\begin{array}{l}\text { modified derivative) } \\
\text { HYNIC-LyeTx I (N-terminal } \\
\text { modified derivative) }\end{array}$ & $5.05 \mu \mathrm{mol}^{-1}$ & $10.10 \mu \mathrm{mol} \mathrm{L}^{-1}$ \\
\hline
\end{tabular}

Values are expressed as median $(n=3)$. $N /$ no inhibition

The radiolabeling procedure with ${ }^{99 \mathrm{~m}} \mathrm{Tc}$ can generate two main radiochemical impurities, ${ }^{99 \mathrm{~m}} \mathrm{TcO}_{2}$ and ${ }^{99 \mathrm{~m}} \mathrm{TcO}_{4}^{-}$. High amounts of these entities may impair imaging data interpretation, once they accumulate in liver/spleen and in thyroid/stomach, respectively [18]. Therefore, it is important to determine and to optimize the radiochemical purity, which means the percentage of ${ }^{99 \mathrm{~m}} \mathrm{Tc}$ atoms that effectively bind the radiopharmaceutical molecules.

Herein, the radiolabeling of the peptide LyeTx I-KHYNIC derivative with ${ }^{99 \mathrm{~m}} \mathrm{Tc}$ atoms was standardized taking into account some parameters: amount of peptide derivative, reducing agent, $\mathrm{pH}$ and heating (Table 3 ). ${ }^{99} \mathrm{~m}_{\mathrm{CcO}}$ molecules are retained at the point of application $\left(R_{f}=0.0\right)$ in both solvents, MEK and acetonitrile:water $(1: 1 ; \mathrm{v}: \mathrm{v})$, once they form a colloid. In contrast, ${ }^{99} \mathrm{~m}_{\mathrm{TcO}} \mathrm{O}_{4}^{-}$migrates to the top of silica gel strip $\left(\mathrm{R}_{\mathrm{f}}=0.9-\right.$ 1.0) in both solvents. LyeTx I-K-HYNIC- ${ }^{99 m} \mathrm{Tc}$ is a hydrophilic compound and thus it remains at the point of application when MEK is used as eluent and it migrates to the top of the silica gel strip with acetonitrile:water $(1: 1 ; \mathrm{v}: \mathrm{v})$. Then, the later eluent was used to determine the amount of ${ }^{99 \mathrm{~m}} \mathrm{TcO}_{2}$, whereas the former was used to quantify ${ }^{99 m} \mathrm{TcO}_{4}^{-}$.

The radiochemical purity analysis (Table 3 ) showed that the radiolabeling procedure either with 10 or $20 \mu \mathrm{g}$ of the peptide LyeTx I-K-HYNIC derivative presented a radiolabeling yield greater than that obtained when $5 \mu \mathrm{g}$ of the peptide derivative was used. Then, the amount of $10 \mu \mathrm{g}$ of the peptide LyeTx I-K-HYNIC derivative was selected for the next steps. Concerning to the reducing agent, $\mathrm{SnCl}_{2} 2 \mathrm{H}_{2} \mathrm{O}$, no significant differences in radiochemical purity was observed between the employed quantities. However, when $250 \mu \mathrm{g}$ of $\mathrm{SnCl}_{2} 2 \mathrm{H}_{2} \mathrm{O}$ was used, it was verified the lowest values of both impurities ${ }^{99 \mathrm{~m}} \mathrm{TcO}_{2}$ and ${ }^{99 \mathrm{~m}_{\mathrm{TcO}}} \mathrm{Tc}_{4}^{-}$. Thus, $250 \mu \mathrm{g}$ of $\mathrm{SnCl}_{2} 2 \mathrm{H}_{2} \mathrm{O}$ was selected in order to perform the other assays. Moreover, results showed that the optimal $\mathrm{pH}$ is between 6 and 8 . Then, for in vivo experiments the $\mathrm{pH}=7$ was chosen. Finally, the radiolabeling process needed water bath heating $\left(100^{\circ} \mathrm{C}\right)$ for at least $15 \mathrm{~min}$. As a result, the optimal radiolabeling procedure (10 $\mu \mathrm{g}$ of the peptide LyeTx I-K-HYNIC derivative; $250 \mu \mathrm{g}$ of $\mathrm{SnCl}_{2} 2 \mathrm{H}_{2} \mathrm{O} ; \mathrm{pH}=7$; heating for $15 \mathrm{~min}$ at $100{ }^{\circ} \mathrm{C}$ ) yielded a radiochemical purity of $87 \pm 1 \%$ ( $n=$ 3 ) and the final preparation presented a specific activity of $37 \mathrm{MBq} / \mathrm{mL}$.

\section{LyeTx I-K-HYNIC- ${ }^{99 m}$ Tc evaluation}

Besides radiochemical purity analysis, LyeTx I-KHYNIC- ${ }^{-9 m}$ Tc was evaluated by RP-HPLC in association with radioactivity measurement of the collected fractions (Fig. 4). First, the peptide LyeTx I-K-HYNIC derivative and the co-ligands (EDDA and tricine) were separately injected and detected at $214 \mathrm{~nm}$ (Fig. 4a). Afterwards, radiolabeled compound was injected and its fractions were collected. The radioactivity was measured in an automatic gamma counter (Fig. $4 \mathrm{~b}$ ) and the results revealed that the radioactivity was associated with the coligands, instead of the peptide LyeTx I-K-HYNIC derivative. These data indicate instability of the radiolabeled complex, suggesting ${ }^{99 \mathrm{~m}} \mathrm{Tc}$ transchelation from the peptide LyeTx I-K-HYNIC derivative to the co-ligands

Table 3 Radiolabeling standardization of the synthetic peptide LyeTx I-K-HYNIC derivative with ${ }^{99 m}$ TC

\begin{tabular}{|c|c|c|c|c|c|}
\hline Amount of LyeTx I-K-HYNIC $\left(\mathrm{SnCl}_{2} 2 \mathrm{H}_{2} \mathrm{O}=200 \mu \mathrm{g} ; \mathrm{pH}=7 ; \Delta=15 \mathrm{~min}\right)$ & $5 \mu \mathrm{g}$ & & $10 \mu \mathrm{g}$ & & $20 \mu \mathrm{g}$ \\
\hline RP (\%) & $73 \pm 3^{\mathrm{a}}$ & & $83 \pm 1^{\mathrm{b}}$ & & $82 \pm 1^{\mathrm{b}}$ \\
\hline Amount of $\mathrm{SnCl}_{2} 2 \mathrm{H}_{2} \mathrm{O}$ (LyeTx I-K-HYNIC $\left.=10 \mu \mathrm{g} ; \mathrm{pH}=7 ; \Delta=15 \mathrm{~min}\right)$ & $100 \mu \mathrm{g}$ & & $200 \mu \mathrm{g}$ & $250 \mu \mathrm{g}$ & $300 \mu \mathrm{g}$ \\
\hline $\mathrm{RP}(\%)$ & $82 \pm 2$ & & $83 \pm 1$ & $87 \pm 1$ & $82 \pm 3$ \\
\hline${ }^{99 m} \mathrm{TcO}_{2}(\%)$ & $9 \pm 1^{a}$ & & $9 \pm 1^{a}$ & $8 \pm 0^{a}$ & $14 \pm 2^{b}$ \\
\hline${ }^{99 \mathrm{~m}} \mathrm{TCO}_{4}^{-}(\%)$ & $8 \pm 1^{a}$ & & $8 \pm 0^{\mathrm{a}}$ & $5 \pm 1^{\mathrm{b}}$ & $4 \pm 1^{\mathrm{b}}$ \\
\hline $\mathrm{pH}\left(\right.$ LyeTx I-K-HYNIC $=10 \mu \mathrm{g} ; \mathrm{SnCl}_{2} 2 \mathrm{H}_{2} \mathrm{O}=250 \mu \mathrm{g} ; \Delta=15 \mathrm{~min}$ ) & 5 & 6 & 7 & 8 & 9 \\
\hline $\mathrm{RP}(\%)$ & $77 \pm 2^{a}$ & $88 \pm 2^{b}$ & $87 \pm 1^{b}$ & $83 \pm 0^{b}$ & $72 \pm 3^{c}$ \\
\hline Heating $\left(100^{\circ} \mathrm{C}\right)\left(\mathrm{LyeTx} \mathrm{I}-\mathrm{K}-\mathrm{HYNIC}=10 \mu \mathrm{g} ; \mathrm{SnCl}_{2} 2 \mathrm{H}_{2} \mathrm{O}=250 \mu \mathrm{g} ; \mathrm{pH}=7\right)$ & $5 \mathrm{~min}$ & & $15 \mathrm{~min}$ & $30 \mathrm{~min}$ & Unheated \\
\hline $\mathrm{RP}(\%)$ & $71 \pm 2^{\mathrm{a}}$ & & $87 \pm 1^{\mathrm{b}}$ & $81 \pm 1^{\mathrm{b}}$ & $57 \pm 4^{c}$ \\
\hline
\end{tabular}

Values are expressed as 'mean $\pm \mathrm{SD}^{\prime}(n=3)$. Different letters indicate significant differences $(p<0.05) . R P$ radiochemical purity 


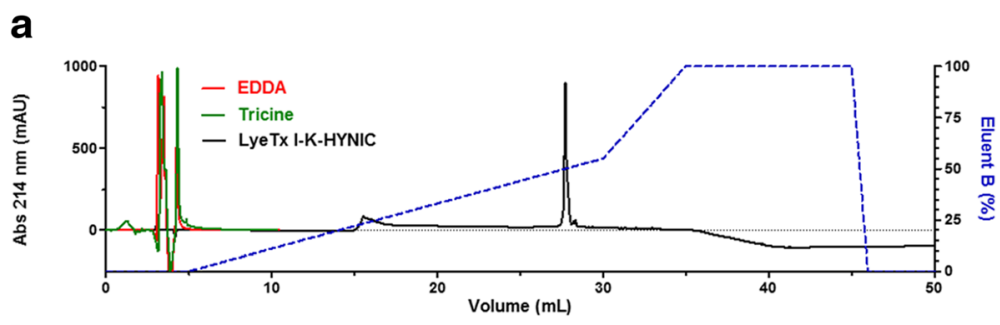

b

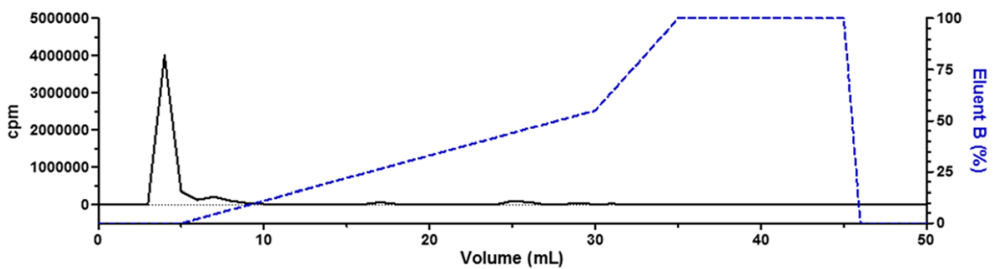

Fig. 4 LyeTX I-K-HYNIC- ${ }^{99 m}$ TC evaluation by RP-HPLC (717 Plus Autosampler, Waters, USA) associated with radioactivity determination of the collected fractions by automatic gamma counter (Wizard, Finland). a Chromatograms of EDDA (red line), tricine (green line) and LyeTx I-K-HYNIC (black line): ACE 5 C8 column ( $5 \mu \mathrm{m}, 250.0 \mathrm{~mm} \times 4.6 \mathrm{~mm}$ ) equilibrated with $0.1 \%(\mathrm{v}: \mathrm{v})$ TFA in water (eluent A) and eluted by a linear gradient of $0.1 \%$ (v:v) TFA in acetonitrile (eluent B); the flow was $1.0 \mathrm{~mL} \cdot \mathrm{min}^{-1}$ and the detection was at $214 \mathrm{~nm}$. b Radiochromatogram of LyeTx I-K-HYNIC--99m TC: ACE 5 C8 column $(5 \mu \mathrm{m}, 250.0 \mathrm{~mm} \times 4.6 \mathrm{~mm}$ ) equilibrated with $0.1 \%$ ( $\mathrm{v}: \mathrm{v})$ TFA in water (eluent A) and eluted by a linear gradient of $0.1 \%$ (v:v) TFA in acetonitrile (eluent B); the flow was $1.0 \mathrm{~mL} \cdot \mathrm{min}^{-1}$. cpm: counts per minute

employed in this reaction. Although other authors had reported the importance of the co-ligands as stabilizing agents in the radiolabeling process, our findings did not show beneficial effects in this specific case $[11,19,20]$. Actually, it is related that EDDA is a strong chelating agent and, then, it might favor the transchelation, which is defined as the metal ${ }^{99 \mathrm{~m}} \mathrm{Tc}$ exchange from a weaker chelating agent to a stronger one [12, 21]. Therefore, further studies will be necessary to improve radiolabeling conditions in order to reach a better stability of LyeTx I-K-HYNIC- ${ }^{-99 \mathrm{~m}}$ Tc.

\section{Conclusions}

In summary, two peptide LyeTx I derivatives modified with the chelating agent HYNIC were synthesized, HYNIC-LyeTx I (N-terminal modification) and LyeTx IK-HYNIC (C-terminal modification). The synthetic crude products were properly purified by RP-HPLC, as shown by MALDI-ToF-MS and RP-HPLC analyses. In vitro assay revealed that the attachment of HYNIC in the C-terminal portion of peptide LyeTx I did not compromise its antimicrobial activity and that the $\mathrm{N}$ terminal portion is important for its interaction with bacteria. However, radiolabeling procedure conditions must be better investigated in order to optimize the process concerning to the binding between ${ }^{99 \mathrm{~m}} \mathrm{Tc}$ and the chelating agent HYNIC. Thus, this complex could be evaluated as a specific imaging agent to distinguish septic and aseptic inflammation.

\section{Abbreviations}

LyeTx I: cationic peptide isolated from Lycosa erythrognatha venom; C-terminal: carboxyl-terminal; E. coli: Escherichia coli; S. aureus: Staphylococcus aureus; ${ }^{99 m} \mathrm{Tc}$ : technetium-99m; ${ }^{99} \mathrm{Mo} /{ }^{99 \mathrm{~m}} \mathrm{Tc}$ generator: molibdenium-99/ technetium-99m generator; HYNIC: 2-hydrazinonicotinamide; N-terminal: nitrogen-terminal; EDDA: ethylene diamine-N,N'-diacetic acid; TFA: trifluoroacetic acid; DMF: N,N-dimethylformamide; RP-HPLC: reverse phase-high performance liquid chromatography; ATCC: American type culture collection; HYNIC-LyeTx I: peptide LyeTx I derivative with the chelating agent HYNIC attached to its N-terminal residue; LyeTX I-K-HYNIC: peptide LyeTx I derivative with the chelating agent HYNIC attached to the lateral amino group of an extra lysine residue coupled to the C-terminal portion; Fmoc: N-9-fluorenylmethyloxycarbonyl; v:v: volume per volume; MALDI-ToF-MS: matrix-assisted laser desorption ionization time of flight mass spectrometer; MS: mass spectrometer; TSB: tryptic soy broth; MIC: minimum inhibitory concentration; NaCl: sodium chloride; w:V: weight per volume; $\mathrm{SnCl}_{2} 2 \mathrm{H}_{2} \mathrm{O}$ : stannous chloride dehydrate; $\mathrm{HCl}$ : hydrochloric acid; $\mathrm{Na}^{99 \mathrm{~m}} \mathrm{TcO}_{4}$ : sodium pertechnetate; q.S. ad: quantity sufficient added; MEK: methyl ethyl ketone; ${ }^{99 \mathrm{~m}} \mathrm{TCO}_{4}^{-}$: free technetium; ${ }^{99 \mathrm{~m}} \mathrm{TCO}_{2}$ : hydrolyzed technetium; SD: standard deviation; ANOVA: analysis of variance; $\mathrm{M}_{\mathrm{w}}$ : molecular weight; CF: collected fraction; PP: peak of peptide; Nl: no inhibition; RP: radiochemical purity; cpm: counts per minute.

\section{Competing interests}

The authors declare that they have no competing interests.

\section{Authors' contributions}

NGSP synthesized both peptide LyeTX I derivatives. LLF and DMS purified synthetic crude peptide LyeTx I derivatives and performed RP-HPLC and MALDI-ToF-MS analysis. LLF assessed in vitro antimicrobial activity, radiolabeled LyeTX I-K-HYNIC derivative with ${ }^{99 \mathrm{~m}} \mathrm{Tc}$ and performed radiochemical purity analysis. LLF, RSA and ALBB evaluated the stability of LyeTX I-K-HYNIC- ${ }^{99 m}$ TC. LLF worked on the statistical analysis. JMR, SOAF, MEL and VNC participated in the design and guidance of the study. LLF wrote the manuscript. All authors read and approved the final manuscript.

\section{Acknowledgements}

The authors would like to thank the undergraduate students Eduardo and Livia for their support in some steps that were not covered in this manuscript, but were important as pilot studies. Thanks are also due to the 
Nuclear Medicine sector of Clinical Hospital of Federal University of Minas Gerais for the supply of ${ }^{99 m} \mathrm{Tc}$.

\section{Funding}

The authors would like to thank the Toxinology Network sponsored by the Coordination for the Improvement of Higher Education Personnel (CAPES) for the PhD fellowship, as well as National Council for Scientific and Technological Development (CNPq), the State of Minas Gerais Research Foundation (FAPEMIG) and the Office of the Dean for Research of the Federal University of Minas Gerais (PRPq/UFMG) for their grants. Thanks are also due to the Center for the Study of Venoms and Venomous Animals (CEVAP) of UNESP for enabling the publication of this paper (CAPES, grant no. 23038.006285/2011-21, AUXPE - Toxinologia - 1219/2011).

\section{Author details}

'Department of Clinical and Toxicological Analyses, School of Pharmacy, Federal University of Minas Gerais, Av. Antônio Carlos, 6627, Belo Horizonte, MG 31270-901, Brazil. ²Department of Biochemistry and Immunology, Institute of Biological Sciences, Federal University of Minas Gerais, Belo Horizonte, MG, Brazil. ${ }^{3}$ Department of Chemistry, Institute of Exact Sciences, Federal University of Minas Gerais, Belo Horizonte, MG, Brazil.

Received: 15 January 2016 Accepted: 12 April 2016

Published online: 22 April 2016

\section{References}

1. Signore A, Glaudemans AW. The molecular imaging approach to image infections and inflammation by nuclear medicine techniques. Ann Nucl Med. 2011;25(10):681-700.

2. Ferreira DS, Boratto FA, Cardoso VN, Serakides R, Fernandes SO, Ferreira LA, et al. Alendronate-coated long-circulating liposomes containing

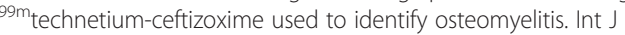
Nanomedicine. 2015:10:2441-50.

3. Signore A, Glaudemans AWJM, Galli F, Rouzet F. Imaging infection and inflammation. BioMed Res Int. 2015;2015:615150. doi:10.1155/2015/615150.

4. Tsopelas C. Radiotracers used for the scintigraphic detection of infection and inflammation. Sci World J. 2015:2015:676719. doi:10.1155/2015/676719.

5. Akhtar MS, Imran MB, Nadeem MA, Shahid A. Antimicrobial peptides as infection imaging agents: better than radiolabeled antibiotics. Int J Pept 2012;2012:965238. doi:10.1155/2012/965238

6. Ferro-Flores G, Ocampo-García BE, Melendez-Alafort L. Development of specific radiopharmaceuticals for infection imaging by targeting infectious micro-organisms. Curr Pharm Des. 2012;18(8):1098-106.

7. Fazli A, Salouti M. Targeting molecular imaging approach for detection of infection and inflammation by diagnostic nuclear medicine techniques. Curr Med Imaging Rev. 2014;10(3):215-33.

8. Santos DM, Verly RM, Piló-Veloso D, de Maria M, de Carvalho MA, Cisalpino PS, et al. LyeTx I, a potent antimicrobial peptide from the venom of the spider Lycosa erythrognatha. Amino Acids. 2010;39(1):135-44.

9. Fani M, Maecke HR. Radiopharmaceutical development of radiolabelled peptides. Eur J Nucl Med Mol Imaging. 2012;39 Suppl 11:S11-30.

10. Pillai MR, Dash A, Knapp Jr FF. Sustained availability of ${ }^{99 \mathrm{~m}} \mathrm{Tc}$ : possible paths forward. J Nucl Med. 2013;54(2):313-23.

11. Lambrecht FY, Durkan K, Bayrak E. Labeling bombesin-like peptide with ${ }^{99 \mathrm{~m}}$ Tc via hydrazinonicotinamide: description of optimized radiolabeling conditions. J Radioanal Nucl Chem. 2010;284(3):539-45.

12. Meszaros LK, Dose A, Biagini SCG, Blower PJ. Hydrazinonicotinic acid (HYNIC) - Coordination chemistry and applications in radiopharmaceutical chemistry. Inorg Chim Acta. 2010;363(6):1059-69.

13. Carlesso FN, Fuscaldi LL, Araújo RS, Teixeira CS, Oliveira MC, Fernandes SOA, et al. Evaluation of ${ }^{99 \mathrm{~m}_{\mathrm{TC}}-\mathrm{HYNIC}-\beta \text { Ala-Bombesin }}(7-14)$ as an agent for pancreas tumor detection in mice. Braz J Med Biol Res. 2015;48(10):923-8.

14. Chan WC, White PD. Fmoc solid phase peptide synthesis: a practical approach. 1st ed. Oxford: Oxford University Press; 2000.

15. CLSI. Performance standards for antimicrobial susceptibility testing; TwentyThird Informational Supplement. CLSI document M100-S23. Wayne: Clinical and Laboratory Standards Institute; 2013.

16. Fuscaldi LL, de Barros ALB, Santos CRP, de Oliveira MC, Fernandes SOA, Cardoso VN. Feasibility of the ${ }^{99 m}$ TC-HYNIC-BAla-Bombesin $(7-14)$ for detection of LNCaP prostate tumour in experimental model. J Radioanal Nucl Chem. 2015;305(2):379-86.
17. de Barros AL, Mota LD, Ferreira CA, Cardoso VN. Kit formulation for ${ }^{99 \mathrm{~m}} \mathrm{TC}$ labeling of HYNIC-BAla-Bombesin(7-14). Appl Radiat Isot. 2012;70(10):2440-5.

18. Fuscaldi LL, de Barros ALB, Santos CRP, de Souza CM, Cassali GD, de Oliveira $M C$, et al. Evaluation of the optimal LNCaP prostate tumour developmental stage to be assessed by ${ }^{99 \mathrm{~m}} \mathrm{TC}-\mathrm{HYNIC}-\beta A l a-$ Bombesin $_{(7-14)}$ in an experimental model. J Radioanal Nucl Chem. 2014;300(2):801-7.

19. Faintuch BL, Teodoro R, Duatti A, Muramoto E, Faintuch S, Smith CJ. Radiolabeled bombesin analogs for prostate cancer diagnosis: preclinical studies. Nucl Med Biol. 2008:35(4):401-11.

20. de Barros ALB, Mota LG, Ferreira CA, Corrêa NCR, de Góes AM, Oliveira MC, et al. ${ }^{99 m}$ Tc-labeled bombesin analog for breast cancer identification. J Radioanal Nucl Chem. 2013;295(3):2083-90.

21. Stalteri MA, Bansal S, Hider R, Mather SJ. Comparison of the stability of technetium-labeled peptides to challenge with cysteine. Bioconjug Chem. 1999:10(1):130-6.

\section{Submit your next manuscript to BioMed Central and we will help you at every step:}

- We accept pre-submission inquiries

- Our selector tool helps you to find the most relevant journal

- We provide round the clock customer support

- Convenient online submission

- Thorough peer review

- Inclusion in PubMed and all major indexing services

- Maximum visibility for your research

Submit your manuscript at www.biomedcentral.com/submit
) Biomed Central 